\title{
The Acute Onset of Autoimmune Hepatitis During Pregnancy in the Absence of Hypergammaglobulinemia and Autoantibodies
}

\author{
Ai Kawada ${ }^{1}$, Shinichi Iwamura ${ }^{1}$, Kenji Yorita ${ }^{2}$, Rikiya Daike ${ }^{1}$, Yu Tanaka ${ }^{3}$, Naoto Kuroda ${ }^{4}$, \\ Yoh Zen ${ }^{5}$, Michiyo Okazaki ${ }^{1}$ and Kunihisa Uchita ${ }^{1}$
}

\begin{abstract}
:
The onset of autoimmune hepatitis (AIH) during pregnancy is rare and often poses a diagnostic challenge. A 29-year-old Japanese woman experienced epigastric pain and nausea during the third trimester of her third pregnancy. Three days after the symptom onset, an emergency Caesarean section was performed because of suspected acute fatty liver of pregnancy; however, the patient's liver dysfunction worsened afterward. Despite normal serum IgG concentration and absence of autoantibodies, biopsy-proven severe hepatitis with centrilobular zonal necrosis and good biochemical response to corticosteroids led to a diagnosis of AIH. Therefore, AIH should be included in the differential diagnosis of liver dysfunction during pregnancy.
\end{abstract}

Key words: autoimmune hepatitis, pregnancy, acute hepatitis, centrilobular zonal necrosis

(Intern Med Advance Publication)

(DOI: 10.2169/internalmedicine.7155-21)

\section{Introduction}

Autoimmune hepatitis (AIH) is clinicopathologically characterized by liver dysfunction with elevated autoantibodies, hypergammaglobulinemia, and lymphoplasmacytic interface hepatitis (1). Its onset during pregnancy is rare, likely because the pregnancy status normally suppresses the immune system. In fact, only 11 patients with the onset of AIH during pregnancy have been reported to date (2-8). The diagnosis of acute onset or early-phase AIH may be difficult because of the absence of the characteristic clinicopathological features of AIH described above (9). Centrilobular (perivenular or Rappaport zone 3) zonal necrosis (CZN) is a minor pathological finding of $\mathrm{AIH}$ and has not been included in the proposed criteria for the diagnosis of AIH $(10,11)$; however, recent data have elevated the importance of CZN in diagnosing $\mathrm{AIH}$, as it is indicative of acute-onset or earlyphase AIH $(9,12-17)$.

We herein report a case of the acute onset of AIH during the patient's third pregnancy. CZN and amelioration of hepatic dysfunction with steroid treatment supported the diagnosis of AIH despite normal serum levels of immunoglobulin $\mathrm{G}(\mathrm{IgG})$ and autoantibodies. We present the detailed clinicopathological findings of our patient and discuss the differential diagnoses within the context of a literature review.

\section{Case Report}

\section{Clinical findings}

A 29-year-old pregnant Japanese woman, gravida 2 para 2 with uterine leiomyoma, was admitted to the hospital because of labor at 38 weeks and 2 days of gestation. She had no history of blood transfusion and had never consumed alcohol or smoked. She was taking no medications; however, she had used iron supplements for 3 days at 31 weeks of gestation due to anemia. The past two pregnancies had been unremarkable; two term neonates without abnormalities had

\footnotetext{
${ }^{1}$ Department of Internal Medicine, Japanese Red Cross Kochi Hospital, Japan, ${ }^{2}$ Department of Diagnostic Pathology, Japanese Red Cross Kochi Hospital, Japan, ${ }^{3}$ Department of Obstetrics and Gynecology, Japanese Red Cross Kochi Hospital, Japan, ${ }^{4}$ Department of Internal Medicine, Kobe Kyodo Hospital, Japan and ${ }^{5}$ Institute of Liver Studies, King's College Hospital and King's College London, UK Received: January 23, 2021; Accepted: February 25, 2021; Advance Publication by J-STAGE: April 12, 2021 Correspondence to Dr. Kenji Yorita, kenjiyorita@gmail.com
} 
Table 1. Laboratory Findings on Hospitalization.

\begin{tabular}{|c|c|c|c|c|c|}
\hline \multicolumn{3}{|l|}{ Complete blood count } & \multicolumn{3}{|l|}{ Blood coagulation test } \\
\hline WBC & $10,300 / \mu \mathrm{L}$ & $(3,500-8,000)$ & PT/PT activity & $15.9 \mathrm{~s} / 56.1 \%$ & $(9-13 / 80-100)$ \\
\hline $\mathrm{RBC}$ & $526 \times 10^{4} / \mu \mathrm{L}$ & $(360-470)$ & PT-INR & 1.4 & $(0.9-1.1)$ \\
\hline $\mathrm{Hb}$ & $12.3 \mathrm{~g} / \mathrm{dL}$ & $(11.0-14.6)$ & APTT & $34.5 \mathrm{~s}$ & $(20-35)$ \\
\hline \multirow[t]{2}{*}{ Platelet } & $15.2 \times 10^{4} / \mu \mathrm{L}$ & $(12.3-33.1)$ & Fibrinogen & $522 \mathrm{mg} / \mathrm{dL}$ & $(170-410)$ \\
\hline & & & FDP & $15.4 \mu \mathrm{g} / \mathrm{mL}$ & $(<5)$ \\
\hline \multicolumn{3}{|l|}{ Serum chemistry } & \multicolumn{3}{|c|}{ Serum immunological test } \\
\hline AST & $1216 \mathrm{IU} / \mathrm{L}$ & $(10-32)$ & CRP & $0.93 \mathrm{mg} / \mathrm{dL}$ & $(0.0-0.16)$ \\
\hline ALT & $1091 \mathrm{IU} / \mathrm{L}$ & $(5-27)$ & $\mathrm{IgG}$ & $765 \mathrm{mg} / \mathrm{dL}$ & $(893-1,838)$ \\
\hline LDH & $467 \mathrm{IU} / \mathrm{L}$ & $(106-211)$ & $\operatorname{IgM}$ & $278 \mathrm{mg} / \mathrm{dL}$ & $(30-195)$ \\
\hline ALP & $488 \mathrm{IU} / \mathrm{L}$ & $(109-344)$ & $\operatorname{IgA}$ & $211 \mathrm{mg} / \mathrm{dL}$ & $(102-396)$ \\
\hline$\gamma$-GTP & $14 \mathrm{IU} / \mathrm{L}$ & $(8-45)$ & ANA & $<40$ & $(<40)$ \\
\hline T-Bil & $7.2 \mathrm{mg} / \mathrm{dL}$ & $(0.3-1.3)$ & ASMA & $<20$ & $(<40)$ \\
\hline D-Bil & $4.0 \mathrm{mg} / \mathrm{dL}$ & $(0.0-0.22)$ & Anti-LKM1 Ab & $(-)$ & \\
\hline BUN & $4.8 \mathrm{mg} / \mathrm{dL}$ & $(8.0-20.0)$ & Anti-cardiolipin Ab & $3 \mathrm{U} / \mathrm{mL}$ & $(<10)$ \\
\hline Creatinine & $0.45 \mathrm{mg} / \mathrm{dL}$ & $(0.36-1.06)$ & AMA-M2 & $(-)$ & \\
\hline $\mathrm{CPK}$ & $50 \mathrm{IU} / \mathrm{L}$ & $(43-165)$ & Free T3 & $2.23 \mathrm{pg} / \mathrm{mL}$ & $(1.71-3.71)$ \\
\hline Amylase & 71 IU/L & $(28-99)$ & Free T4 & $1.18 \mathrm{ng} / \mathrm{dL}$ & $(0.70-1.48)$ \\
\hline $\mathrm{Na}$ & $134 \mathrm{mEq} / \mathrm{L}$ & $(135-150)$ & TSH & $1.26 \mu \mathrm{IU} / \mathrm{mL}$ & $(0.35-4.94)$ \\
\hline $\mathrm{Cl}$ & $107 \mathrm{mEq} / \mathrm{L}$ & $(98-108)$ & HGF & $0.68 \mathrm{ng} / \mathrm{mL}$ & $(<0.39)$ \\
\hline K & $3.4 \mathrm{mEq} / \mathrm{L}$ & $(3.5-5.0)$ & HLA & DR8 & (DRB $1 * 08$ allele) \\
\hline NH3 & $62 \mu \mathrm{g} / \mathrm{dL}$ & $(12-66)$ & & & \\
\hline \multirow[t]{2}{*}{ Glu } & $77 \mathrm{mg} / \mathrm{dL}$ & $(65-109)$ & Viral markers & & \\
\hline & & & $\mathrm{HA} \mathrm{Ab}$ & $(-)$ & \\
\hline \multicolumn{3}{|l|}{ Urinalysis } & IgM anti-HAV & $(-)$ & \\
\hline $\mathrm{pH}$ & 6.5 & & $\mathrm{HBs} \mathrm{Ag}$ & $(-)$ & \\
\hline Specific gravity & 1.023 & & anti-HCV Ab & $(-)$ & \\
\hline Urine occult blood & $(-)$ & & HCV RNA & $(-)$ & \\
\hline Urine protein & $(1+)$ & & IgA anti-HEV & $(-)$ & \\
\hline Urine bilirubin & $(1+)$ & & IgM anti-CMV & $(-)$ & \\
\hline Urine ketone & $(-)$ & & IgG anti-CMV & $(-)$ & \\
\hline \multirow[t]{5}{*}{ Urine urobilinogen } & $(1+)$ & & IgM anti-HSV & $(-)$ & \\
\hline & & & IgG anti-HSV & $(-)$ & \\
\hline & & & IgM anti-EBV VCA & $<10$ & $(<10)$ \\
\hline & & & IgG anti-EBV VCA & $\times 160$ & $(<10)$ \\
\hline & & & Anti-EBNA & $\times 40$ & $(<10)$ \\
\hline
\end{tabular}

Numbers in parentheses are the reference ranges.

WBC: white blood cells, RBC: red blood cells, Hb: hemoglobin, AST: asparate aminotransferase, ALT: alanine aminotransferase, LDH: lactate dehydrogenase, ALP: alkaline phosphatase, $\gamma$-GTP: $\gamma$-glutamyltransferase, T-Bil: total bilirubin, D-Bil: direct bilirubin, BUN: blood urea nitrogen, CPK: creatine phosphokinase, Glu: glucose, PT: prothrombin time, INR: international normalized ratio, APTT: activated partial thromboplastin time, FDP: fibrin degenerated products, CRP: C-reactive protein, Ig: immunoglobulin, ANA: anti-nuclear antibody, ASMA: anti-smooth muscle antibody, Anti-LKM1 Ab: anti-liver kidney microsome 1 antibody, AMA-M2: anti-mitochondrial antibody subtype M2, TSH: thyroidstimulating hormone, HGF: hepatocyte growth factor, HA Ab: hepatitis A antibody, HAV: hepatitis A virus, HBs Ag: hepatitis B surface antigen, HBc: hepatitis B core, HCV: hepatitis C virus, HEV: hepatitis E virus, CMV: cytomegalovirus, HSV: herpes simplex virus, EBV: Epstein-Barr virus, VCA: virus capsid antigen

been born vaginally. She had experienced no adverse clinical events during her third pregnancy until she experienced epigastric pain and nausea beginning at 37 weeks and 6 days of gestation.

On admission, her blood pressure was 113/64 mmHg, and other vital signs were normal (she was not comatose). Her pre-pregnancy body mass index had been $23.4 \mathrm{~kg} / \mathrm{m}^{2}$, and she had gained $8 \mathrm{~kg}$ during pregnancy. A physiological examination revealed jaundice without pruritic skin lesions or edema. The patient's laboratory test results are summarized in Table 1. She had elevated serum levels of total bilirubin, aspartate aminotransferase (AST), and alanine aminotransferase (ALT). Her ammonia level and platelet count were within normal ranges. Coagulation tests showed an elongated prothrombin time, while renal function tests were normal. Ultrasonography revealed no fatty liver or hepatic atrophy, and no ascites was present.

Acute fatty liver of pregnancy (AFLP) was suspected owing to the elongated prothrombin time, and an emergency Caesarean section was performed at 38 weeks and 2 days of 


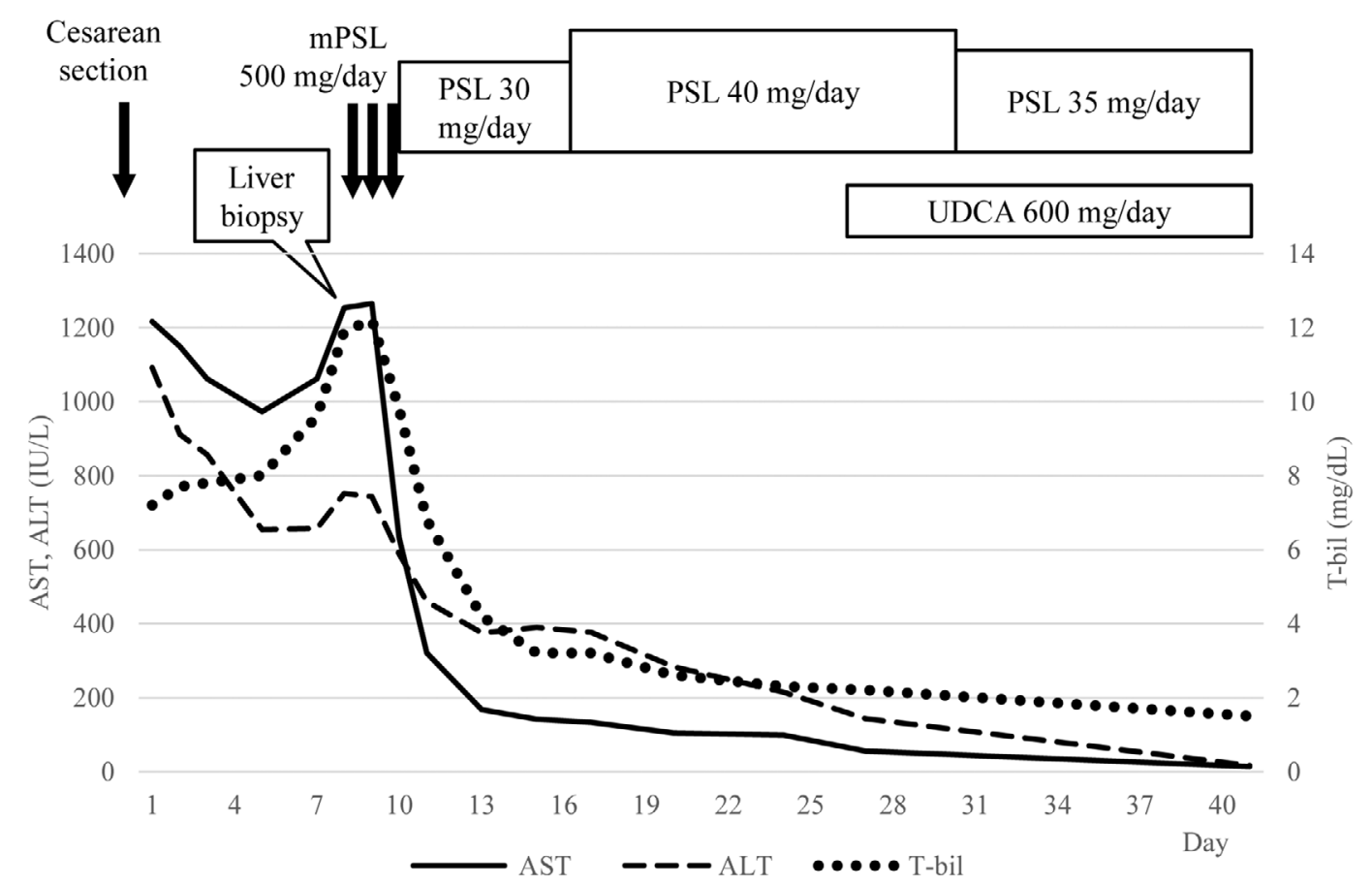

Figure 1. Clinical course of hospitalization after Caesarean section. ALT: alanine aminotransferase, AST: aspartate aminotransferase, mPSL: methylprednisolone, PSL: prednisolone, T-bil: total bilirubin, UDCA: ursodeoxycholic acid

gestation. A 2,660-g female neonate was delivered with Apgar scores of 8 and 9 at 1 and 5 minutes, respectively. The neonate showed no abnormalities on a physical examination or laboratory tests.

Following delivery, the patient's serum AST and ALT levels decreased slightly for several days without treatment. However, her total bilirubin level mildly increased (Fig. 1). Serological test results indicated neither prior nor current infections with hepatitis $\mathrm{A}$, hepatitis $\mathrm{B}$, hepatitis $\mathrm{C}$, or hepatitis $\mathrm{E}$ viruses, herpes simplex virus, cytomegalovirus, or Epstein-Barr virus. Although $\mathrm{AIH}$ was suspected, the IgG and autoantibody levels, including anti-nuclear antibodies (ANA), were within normal range. The human leukocyte antigen (HLA) DR8 serotype was detected. Seven days after the Caesarean section, the serum levels of AST and total bilirubin increased, and reached pre-Caesarean section levels by the eighth day (Fig. 1). Thus, AFLP appeared to be unlikely. Steroid therapy was started 8 days after the Caesarean section (following a core needle biopsy of the liver); methylprednisolone $500 \mathrm{mg} /$ day was administered for three days, followed by the oral administration of 30-40 mg/day of prednisolone (Fig. 1).

Serum transaminase and bilirubin levels returned to normal within one month after commencing treatment (Fig. 1). AIH was deemed probable because 14 and 16 aggregate points were obtained before and after steroid therapy, respectively, per the criteria for the diagnosis of $\mathrm{AIH}$ as revised in 1999 (10). However, AIH could not be confirmed when using the simplified diagnostic 2008 criteria for AIH because only three points were met (a minimum of six points are required for a probable diagnosis) (11). Ulti- mately, AIH was diagnosed after ruling out other liver disorders and based on pathological findings, as well as the fact that the liver function rapidly recovered after steroid therapy.

The oral administration of prednisolone was tapered, and the patient continued to be treated with low-dose prednisolone $(5 \mathrm{mg} /$ day $)$. Her condition remained stable with neither flare-ups nor occurrence of autoimmune disease other than AIH for three years after her Caesarean section. Her serum $\mathrm{IgG}$ and ANA levels were within normal range during the three-year follow-up period. No developmental issues were seen in her child.

\section{Pathological findings}

A core needle biopsy of the liver predominantly showed features of lobular hepatitis (Fig. 2A, B). The necroinflammatory changes were particularly severe in the perivenular area; multiple foci of $\mathrm{CZN}$ were observed. The periportal parenchyma was damaged with scattered foci of lymphocytic infiltration and acidophilic bodies. Portal inflammation was mild, and interface hepatitis was focally observed. The inflammatory infiltrate consisted of predominantly lymphocytes, and plasma cells were rare. Hepatocellular rosettes and emperipolesis were inconspicuous, and no bridging fibrosis was detected. Neither cholangitis nor concentric fibrosis around the bile ducts was found, and no steatosis or cholestasis was observed. Fibrinoid necrosis was not detected in the vessels, and no periportal necrosis with intrasinusoidal fibrin deposition was observed. Immunohistochemically, adipophilin staining did not identify abundant intracytoplasmic lipid droplets in hepatocytes, and none of the cells were positive for anti-cytomegalovirus or anti-herpes simplex vi- 

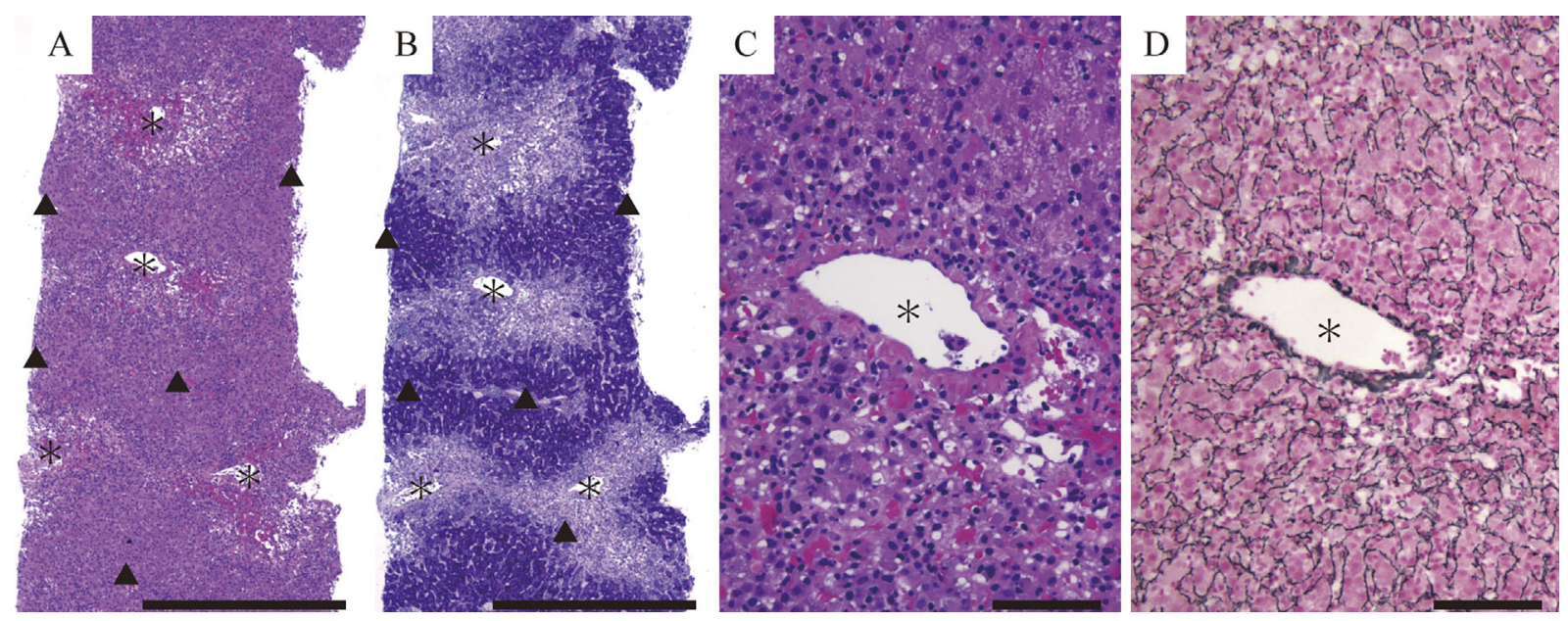

Figure 2. Microscopic findings of the core needle liver biopsy sample obtained from our patient with autoimmune hepatitis. A-B: Low-magnification image of the liver sample [A, Hematoxylin and Eosin (H\&E) staining section; B, periodic acid-Schiff-stained section]. Zonal hepatocellular necrosis was noted in the centrilobular (perivenular, zone 3 ) regions indicated by asterisks. In panel $B$, the purple-stained areas (including the portal areas indicated by triangles) show hepatocellular cords of glycogen-rich hepatocytes. Non-purple areas, including central venules, correspond to a loss of hepatocytes. C-D: High-magnification image of the centrilobular area (C, H\&E staining section; D, section prepared using the silver impregnation method). Loss of hepatocytes was observed around a central venule, while the reticular fibers along the hepatic cords were preserved. Steatosis is inconspicuous in residual hepatocytes. Scale bar: $1 \mathrm{~mm}$ in A-B; $100 \mu \mathrm{m}$ in C-D.

rus type 1 antibodies. Epstein-Barr virus infection was unlikely owing to the lack of Epstein-Barr virus-encoding small RNA 1 detection by in situ hybridization. The pathological findings were thus consistent with the acute onset or early manifestation of AIH.

\section{Discussion}

The acute liver damage experienced by our pregnant patient markedly improved with steroid therapy that commenced eight days after her Caesarean section. The time of the onset of her liver damage was unknown but was assumed to be during the third trimester of pregnancy, considering that symptoms started at 37 weeks and 6 days of gestation and a liver biopsy exhibited no apparent fibrosis. The potential causes of such liver damage can usually be attributed to drugs, viral hepatitis, pregnancy-related diseases, and AIH (18). However, drug usage and viral hepatitis were ruled out in our patient. Wilson's disease was also considered unlikely due to her responsiveness to steroid therapy.

Hepatic diseases unique to pregnancy include hyperemesis gravidarum, intrahepatic cholestasis of pregnancy, preeclampsia/eclampsia, AFLP, hemolysis, elevated liver enzymes, and low platelet (HELLP) syndrome (19). In our patient, hyperemesis gravidarum was unlikely because vomiting and weight loss were not observed. Furthermore, the lack of pruritus and intrahepatic cholestasis ruled out intrahepatic cholestasis, while preeclampsia/eclampsia was improbable owing to a lack of hypertension and seizures. Although AFLP was clinically suspected because of the elon- gated prothrombin time, the histological findings were not consistent with this condition. HELLP syndrome could not be diagnosed using Sibai's diagnostic criteria (20). Our patient experienced transient improvement in serum AST and ALT after her Caesarean section, suggesting that some pregnancy-related liver disease might have been present. AIH was the most likely cause of acute liver damage given that her liver function worsened after her pregnancy and that subsequent steroid therapy was remarkably effective.

Although AIH is clinicopathologically characterized by elevated autoantibodies, elevated AST/ALT, hypergammaglobulinemia, and lymphoplasmacytic interface hepatitis (1), autoantibodies and hypergammaglobulinemia were absent in our patient. Typical pathological findings of $\mathrm{AIH}$ include interface hepatitis, predominant lymphoplasmacytic infiltrates, and hepatocellular rosettes $(10,11)$; however, our patient lacked significant plasma cell infiltration and hepatocellular rosettes. CZN and centrilobular necrosis have not been included in the proposed criteria for the diagnosis of AIH $(10,11)$, and both CZN and centrilobular necrosis were reported as minor pathological findings in patients who had AIH, with incidences of 29\% (1) and 13\% (9), respectively. Recent data have elevated the importance of CZN or centrilobular necrosis in diagnosing $\mathrm{AIH}$, as this condition is indicative of acute-onset AIH (9, 12-17). Interestingly, the clinicopathological features of AIH exhibiting CZN included a higher frequency of acute-onset disease, lower titers of ANA, lower levels of IgG, lower grades of interface hepatitis, less prominent lymphoplasmacytic infiltrates, and lower AIH scores (9); these features were observed in our patient. 
Table 2. Previously Described Patients with Autoimmune Hepatitis Onset during Pregnancy.

\begin{tabular}{|c|c|c|c|c|c|c|c|c|c|}
\hline $\begin{array}{l}\text { First author } \\
\text { /published } \\
\text { year }\end{array}$ & $\begin{array}{l}\text { Patient age } \\
\text { (years)/ } \\
\text { gestational } \\
\text { weeks at } \\
\text { AIH onset }\end{array}$ & $\begin{array}{l}\text { Gravida } \\
(\mathrm{G}) \text { and } \\
\text { para }(\mathrm{P}) / \\
\text { HLA-DR }\end{array}$ & $\begin{array}{c}\text { Timing of AIH } \\
\text { diagnosis }\end{array}$ & $\begin{array}{c}\text { AST/ALT/T-bil/ } \\
\text { D-bil level at } \\
\text { onset of AIH }\end{array}$ & $\begin{array}{c}\mathrm{IgG} \\
(\mathrm{mg} / \mathrm{dL})\end{array}$ & ANA & $\begin{array}{l}\text { Pathological } \\
\text { findings }\end{array}$ & Therapy/effect & $\begin{array}{l}\text { Baby/birth week/ } \\
\text { birth method }\end{array}$ \\
\hline $\begin{array}{l}\text { Heneghan, } \\
2001\end{array}$ & $24 / 16$ & $\begin{array}{c}\text { G(NA)P3/ } \\
\text { NA }\end{array}$ & & NA & & & $\begin{array}{c}\text { Characteristic } \\
\text { findings }\end{array}$ & PSL/effective & NA \\
\hline $\begin{array}{l}\text { Heneghan, } \\
2001\end{array}$ & $28 / 24$ & NA/NA & \multicolumn{5}{|c|}{ NA (severe AIH) } & $\begin{array}{c}\text { Steroid } \\
\text { therapy was } \\
\text { not performed } \\
\text { due to sepsis }\end{array}$ & $\begin{array}{l}\text { Serous physical } \\
\text { and mental } \\
\text { developmental } \\
\text { difficulties/28/ } \\
\text { CS }\end{array}$ \\
\hline
\end{tabular}

Floreani, $\quad$ NA (Four patients had onset of AIH during pregnancy, and the outcome of pregnancy in these patients was favorable)

2006

Oi, 2008

G2P1/NA

16 gestational

$1433 / 1202 /$

$\underline{1,946}$

NA
[Anti-
LKM1

$\mathrm{IH}(+)$

PSL/

improved

$1170 \mathrm{~g}, \mathrm{LDH}$,

LKM1

\begin{tabular}{|c|c|c|c|c|c|c|c|c|c|}
\hline $\begin{array}{l}\text { Fushimi, } \\
2013\end{array}$ & $31 / 14$ & $\begin{array}{l}\text { G(NA)P1/ } \\
\text { HLA-DR4 }\end{array}$ & $\begin{array}{c}1 \text { month after } \\
\text { AA ( } 21 \\
\text { weeks) }\end{array}$ & $\begin{array}{c}\text { NA/344/6.1/4.8 } \\
\text { (20 weeks) }\end{array}$ & $\begin{array}{c}1,103 \\
\text { (after AA) }\end{array}$ & $(-)$ & $\begin{array}{c}\text { IH }(+), \text { PLPI } \\
\quad(+), \text { R (+) } \\
(\text { after AA) }\end{array}$ & $\begin{array}{c}\text { PSL/ } \\
\text { improved }\end{array}$ & AA (21) \\
\hline Sato, 2015 & $25 / 16$ & $\begin{array}{c}\text { NA/ } \\
\text { HLA- } \\
\text { DR9, } 13\end{array}$ & $\begin{array}{l}\text { A few days } \\
\text { after onset }\end{array}$ & $\begin{array}{l}361 / 101 / \\
14.2 / 9.9\end{array}$ & 1,030 & $\underline{\times 80}$ & $\begin{array}{c}\text { IH (+), PLPI } \\
(+), \text { R (+), } \\
\text { CLN (+) }\end{array}$ & $\begin{array}{c}\text { PE, CHDF, } \\
\text { PSL, AZA/ } \\
\text { improved }\end{array}$ & $\begin{array}{c}\text { Healthy } \\
\text { neonate/29/CS }\end{array}$ \\
\hline $\begin{array}{l}\text { Kuwayama, } \\
2016\end{array}$ & $25 / 22$ & G0P0/NA & $\begin{array}{c}\text { NA (PSL } \\
\text { started from } \\
2547 \\
\text { gestational } \\
\text { weeks) }\end{array}$ & $\begin{array}{l}106 / 30 / \\
11.1 / 7.7\end{array}$ & $\underline{3,600}$ & $\times 320$ & $\begin{array}{c}\mathrm{IH}(+), \\
\text { bridging } \\
\text { fibrosis }(+)\end{array}$ & PSL/improved & $\begin{array}{c}1800 \mathrm{~g}, \mathrm{AV} \\
\text { block/32/VD }\end{array}$ \\
\hline $\begin{array}{l}\text { Yoshika, } \\
2016\end{array}$ & $27 / 28$ & G0P0/NA & $\begin{array}{l}1-2 \text { months } \\
\text { after ECS }\end{array}$ & $\begin{array}{l}163 / 102 / \\
21.6 / 16.8\end{array}$ & $\underline{2,062}$ & $\times 640$ & $\begin{array}{l}\text { Plasma cells } \\
\text { in some portal } \\
\text { tracts, MHN } \\
(+)\end{array}$ & $\begin{array}{l}\text { CHDF, PSL/ } \\
\text { improved }\end{array}$ & NA/28/ECS \\
\hline $\begin{array}{l}\text { Our case, } \\
2021\end{array}$ & $29 / 3767$ & $\begin{array}{c}\text { G2P2/ } \\
\text { HLA-DR8 }\end{array}$ & $\begin{array}{c}8 \text { days after } \\
\text { ECS }\end{array}$ & $\begin{array}{c}1216 / 1091 / \\
7.2 / 4.0\end{array}$ & 765 & $<40$ & $\begin{array}{c}\text { IH (+), PLPI } \\
(-), \text { R (-), } \\
\text { CZN (+) }\end{array}$ & $\begin{array}{c}\text { PSL/ } \\
\text { improved }\end{array}$ & $\begin{array}{c}\text { A healthy } \\
\text { female, } 2660 \\
\text { g/38 2//ECS }\end{array}$ \\
\hline
\end{tabular}

The underlined values indicate abnormal data.

HLA: human leukocyte antigen, AIH: autoimmune hepatitis, AST: aspartate aminotransferase, ALT: alanine aminotransferase, T-bil: total bilirubin, D-bil: direct bilirubin, IgG: immunoglobulin G, ANA: antinuclear antibodies, NA: not available, PSL: prednisolone, IH: interface hepatitis, CS: cesarean section, Anti-LKM1 Ab: anti-liver kidney microsome 1 antibody, LDH: light for date, VSD: ventricular septal defect, VD: vaginal delivery, AA: artificial abortion, PLPI: predominant lymphoplasmacytic infiltrate, R: rosetting of liver cells, CLN: centrilobular necrosis, PE: plasma exchange, CHDF: continuous hemodiafiltration, AZA: azathioprine, AV: atrioventricular, ECS: emergency cesarean section, MHN: massive hepatocellular necrosis, CZN: centrilobular zonal necrosis

Therefore, acute-onset or acute hepatitis-like AIH can be challenging to diagnose based solely on clinical findings, with $\mathrm{CZN}$ potentially being the only indicative finding; as such, a pathological evaluation appears to be extremely valuable for making a diagnosis.

However, CZN is not a pathological finding that is specific to $\mathrm{AIH}$, as it can be observed in patients with various other conditions, including adverse drug injury, viral hepatitis, venous outflow block (21), and transplanted liver (22). Taken together, these findings indicate that the presence of $\mathrm{CZN}$ as well as the absence of these other conditions can suggest AIH.

Muratori et al. demonstrated that the 2008 simplified diagnostic criteria for AIH did not diagnose 31\% (22/70 cases) of acute-onset AIH cases that had been diagnosed by the 1999 revised diagnostic criteria (23). At present, acuteonset AIH should be evaluated by the two diagnostic criteria for AIH $(10,11)$, not only by the simplified diagnostic crite- ria (11). Furthermore, newer and better diagnostic criteria for acute-onset AIH may be needed, considering that 70 cases of acute-onset AIH received a diagnosis of 'probable' AIH (54\%, 38 cases) and 'definite' AIH (46\%, 32 cases ) with the 1999 revised diagnostic criterion (23).

Pregnancy usually suppresses the immune system; therefore, only less-intense immunosuppressive therapy can be performed for pregnant AIH patients $(24,25)$. Heneghan et al. reported 35 pregnancies in 18 women in a study of 162 female patients with AIH; 2 patients were diagnosed with AIH during pregnancy (2). Floreani et al. reported that 4 patients $(6.3 \%)$ had the onset of AIH during pregnancy, with favorable outcomes (3). Five other case reports of de novo AIH during pregnancy with detailed clinicopathological features are available in the literature (4-8). A total of 11 patients with AIH onset during pregnancy have been reported previously (Table 2). These findings suggest that AIH can occur in pregnant women, particularly acute-onset $\mathrm{AIH}$, dur- 
ing any trimester, as 4 out of 5 patients (80\%) likely presented with acute-onset AIH (4-8). Similar to the present case, another case with normal levels of IgG and ANA was reported (5). CZN was not described in previous cases, but one patient had massive hepatocellular necrosis (8), while another had centrilobular necrosis (6). Centrilobular necrosis and $\mathrm{CZN}$ can be treated as synonyms, and massive hepatocellular necrosis might have been a severe form of CZN; thus, $\mathrm{CZN}$ and/or centrilobular necrosis might be useful findings in cases with the onset of $\mathrm{AIH}$ during pregnancy. All patients in the previous cases were steroid-sensitive and had preterm infants. While one infant was healthy (6), severe physical and mental developmental difficulties (2), ventricular septal defect (4), or atrioventricular block (7) were found in infants born to three patients, and two infants $(4,7)$ did not seem to have any untreatable developmental defects. The prompt diagnosis and treatment of $\mathrm{AIH}$ with an onset during pregnancy is needed, as AIH can be a risk factor for adverse pregnancy outcomes, such as preterm birth and low-birth-weight children (26); furthermore, $11 \%$ (8/70 cases) of patients with acute-onset AIH required liver transplants or died from the disease (27). Our case with its long-term follow-up is valuable, as previous reports (2-8) did not present follow-up data, or the period was limited to just one year.

The pathogenesis of AIH during pregnancy remains unknown. Interestingly, the onset of AIH has also been reported within one year after delivery $(28,29)$. AIH has also been shown to have a genetic association with HLA-DR4 in Japan and with HLA-DR3 $(30,31)$ and HLA-DR4 in white European and North American populations, respectively (32). In addition, the prevalence of HLA-DR9 was significantly higher in AIH patients with CZN than in those without CZN, whereas the prevalence of HLA-DR4 was significantly lower in $\mathrm{AIH}$ patients with $\mathrm{CZN}$ than in those without CZN (9). In another study, the HLA-DR status was obtained in only 2 of 11 patients with the onset of AIH during pregnancy (Table 2), and 1 patient with centrilobular necrosis was positive for HLA-DR9 (6). The HLA-DR8 detected in our patient was not reported in any of those 11 patients, although the prevalence of HLA-DR8 in AIH patients with CZN of $20 \%$ has been reported to be similar to that in AIH patients without CZN (9). We did not detect autoantibodies related to $\mathrm{AIH}$, potentially suggesting AIH-like pregnancy-triggered hepatitis of unknown etiology. However, unknown or unexamined autoantibodies might have been triggered during pregnancy given that the patient was responsive to immunosuppressive therapy. Considering that there were no liver abnormalities in the fetuses of any of the patients reported to date (4-8), the autoantibodies likely targeted the mother's liver rather than the fetal liver.

Furthermore, the present patient exhibited hyperbilirubinemia. The direct and indirect bilirubin levels were elevated in our patient and five other patients with de novo AIH during pregnancy (4-8). While the cause remained unknown, steroid therapy normalized the abnormal bilirubin levels of our pa- tient and the five previous patients. Although indirect hyperbilirubinemia might indicate Gilbert's syndrome or hemorrhagic anemia, the normalization of our patient's bilirubin levels after steroid treatment and her lack of anemia made both conditions unlikely. Whether or not steroid therapy improves glucuronic acid conjugation has not been reported. Although cholestasis may be improved by steroids, cholestasis was not pathologically detected or indicated in our patient or in the five previous patients. The CZN may have been the cause of hyperbilirubinemia in our case; Hofer et al. reported that bilirubin levels were markedly higher in patients with AIH with centrilobular necrosis than in those without centrilobular necrosis (13). However, this hypothesis has not been confirmed, as Aizawa et al. reported that the total bilirubin levels in patients with AIH with or without CZN were almost normal and not significantly elevated (9).

In summary, we encountered a case of de novo AIH during pregnancy. Steroid therapy was remarkably effective, and she experienced no recurrences during three years of treatment. The acute onset or acute hepatitis-like manifestation of AIH should be included in the differential diagnosis of acute liver damage in pregnant women, even if autoantibodies and IgG are not elevated. Furthermore, AIH should be included in the differential diagnosis of patients with postpartum liver dysfunction. A pathological evaluation appears to be important for diagnosing acute-onset AIH. Additional documentation of similar cases will be needed to clarify the clinicopathological characteristics of such patients, as well as therapeutic options and fetal management.

The authors state that they have no Conflict of Interest (COI).

\section{Acknowledgement}

The authors would like to thank Ms. Keiko Mizuno, Mr. Masahiko Ohara, Ms. Kaoru Yasuoka, and Ms. Yukari Wada for the preparation of histological and immunohistochemical specimens.

\section{Ethics approval}

Written informed consent was obtained from the patient.

\section{References}

1. Mack CL, Adams D, Assis DN, et al. Diagnosis and Management of Autoimmune Hepatitis in Adults and Children: 2019 Practice Guidance and Guidelines From the American Association for the Study of Liver Diseases. Hepatology 72: 671-722, 2020.

2. Heneghan MA, Norris SM, O'Grady JG, Harrison PM, McFarlane IG. Management and outcome of pregnancy in autoimmune hepatitis. Gut 48: 97-102, 2001.

3. Floreani A, Niro G, Rosa Rizzotto E, et al. Type I autoimmune hepatitis: clinical course and outcome in an Italian multicentre study. Aliment Pharmacol Ther 24: 1051-1057, 2006.

4. Ohi Y, Nonaka A, Kadowaki A, et al. A case of a woman with autoimmune hepatitis onsetted during pregnancy. Nihon Sanfujinka Gakkai Kantorengo Tihobukai Kaishi 45: 329-333, 2008 (in Japanese).

5. Fushimi T, Koga H, Kozuma Y, et al. Acute onset autoimmune 
hepatitis in pregnancy complicated with fetal ascites: A case report. Kanzo (Liver) 54: 780-786, 2013 (in Japanese).

6. Sato H, Tomita K, Yasue $\mathrm{C}$, et al. Pregnant woman with noncomatose autoimmune acute liver failure in the second trimester rescued using medical therapy: A case report. Hepatol Res 45: 349-355, 2015.

7. Kuwayama T, Shiga T, Furui T, Terasawa K, Morishige K. Autoimmune hepatitis developed during pregnancy and caused severe jaundice: A case report. Tokai J Obstet Gynecol 53: 145-152, 2016.

8. Yoshika M, Nakano Y, Nakao M, Fukamachi K, Nakamura F. A 28-week-pregnant woman at twenty years of age, who had been hospitalized with jaundice. Rinsho Byori 64: 1091-1098, 2016 (in Japanese).

9. Aizawa Y, Abe H, Sugita T, et al. Centrilobular zonal necrosis as a hallmark of a distinctive subtype of autoimmune hepatitis. Eur J Gastroenterol Hepatol 28: 391-397, 2016.

10. Alvarez F, Berg PA, Bianchi FB, et al. International Autoimmune Hepatitis Group Report: review of criteria for diagnosis of autoimmune hepatitis. J Hepatol 31: 929-938, 1999.

11. Hennes EM, Zeniya M, Czaja AJ, et al. Simplified criteria for the diagnosis of autoimmune hepatitis. Hepatology 48: 169-176, 2008.

12. Zen Y, Notsumata K, Tanaka N, Nakanuma Y. Hepatic centrilobular zonal necrosis with positive antinuclear antibody: a unique subtype or early disease of autoimmune hepatitis? Hum Pathol 38: 1669-1675, 2007.

13. Hofer H, Oesterreicher C, Wrba F, Ferenci P, Penner E. Centrilobular necrosis in autoimmune hepatitis: a histological feature associated with acute clinical presentation. J Clin Pathol 59: 246249, 2006.

14. Te HS, Koukoulis G, Ganger DR. Autoimmune hepatitis: a histological variant associated with prominent centrilobular necrosis. Gut 41: 269-271, 1997.

15. Singh R, Nair S, Farr G, Mason A, Perrillo R. Acute autoimmune hepatitis presenting with centrizonal liver disease: case report and review of the literature. Am J Gastroenterol 97: 2670-2673, 2002.

16. Misdraji J, Thiim M, Graeme-Cook FM. Autoimmune hepatitis with centrilobular necrosis. Am J Surg Pathol 28: 471-478, 2004.

17. Nguyen Canh H, Harada K, Ouchi H, et al. Acute presentation of autoimmune hepatitis: a multicentre study with detailed histological evaluation in a large cohort of patients. J Clin Pathol 70: 961969, 2017.

18. Ostapowicz G, Fontana RJ, Schiodt FV, et al. Results of a prospective study of acute liver failure at 17 tertiary care centers in the United States. Ann Intern Med 137: 947-954, 2002.

19. Brady CW. Liver disease in pregnancy: What's new. Hepatol Commun 4: 145-156, 2020.

20. Sibai BM. The HELLP syndrome (hemolysis, elevated liver en- zymes, and low platelets): much ado about nothing? Am J Obstet Gynecol 162: 311-316, 1990.

21. Birgens HS, Henriksen J, Matzen P, Poulsen H. The shock liver. Clinical and biochemical findings in patients with centrilobular liver necrosis following cardiogenic shock. Acta Med Scand 204: 417-421, 1978.

22. Turlin B, Slapak GI, Hayllar KM, Heaton N, Williams R, Portmann B. Centrilobular necrosis after orthotopic liver transplantation: a longitudinal clinicopathologic study in 71 patients. Liver Transpl Surg 1: 285-289, 1995.

23. Muratori P, Granito A, Lenzi M, Muratori L. Limitation of the simplified scoring system for the diagnosis of autoimmune Hepatitis with acute onset. Liver Int 2021(in press).

24. Buchel E, Van Steenbergen W, Nevens F, Fevery J. Improvement of autoimmune hepatitis during pregnancy followed by flare-up after delivery. Am J Gastroenterol 97: 3160-3165, 2002.

25. Bozward AG, Wootton GE, Podstawka O, Oo YH. Autoimmune Hepatitis: Tolerogenic Immunological State During Pregnancy and Immune Escape in Post-partum. Front Immunol 11: 591380, 2020.

26. Stokkeland K, Ludvigsson JF, Hultcrantz R, et al. Increased risk of preterm birth in women with autoimmune hepatitis - a nationwide cohort study. Liver Int 36: 76-83, 2016.

27. Aljumah AA, Al-Ashgar H, Fallatah H, Albenmousa A. Acute onset autoimmune hepatitis: Clinical presentation and treatment outcomes. Ann Hepatol 18: 439-444, 2019.

28. Izumi Y, Kaneko A, Oku K, et al. Development of liver dysfunction after delivery is possibly due to postpartum autoimmune hepatitis. A report of three cases. J Intern Med 252: 361-367, 2002.

29. Samuel D, Riordan S, Strasser S, Kurtovic J, Singh-Grewel I, Koorey D. Severe autoimmune hepatitis first presenting in the early post partum period. Clin Gastroenterol Hepatol 2: 622-624, 2004.

30. Seki T, Ota M, Furuta S, et al. HLA class II molecules and autoimmune hepatitis susceptibility in Japanese patients. Gastroenterology 103: 1041-1047, 1992.

31. Yoshizawa K, Umemura T, Ota M. Genetic background of autoimmune hepatitis in Japan. J Gastroenterol 46 Suppl 1: 42-47, 2011.

32. de Boer YS, van Gerven NM, Zwiers A, et al. Genome-wide association study identifies variants associated with autoimmune hepatitis type 1. Gastroenterology 147: 443-452 e445, 2014.

The Internal Medicine is an Open Access journal distributed under the Creative Commons Attribution-NonCommercial-NoDerivatives 4.0 International License. To view the details of this license, please visit (https://creativecommons.org/licenses/ by-nc-nd/4.0/).

\section{(C) The Japanese Society of Internal Medicine Intern Med Advance Publication}

